\title{
A focus group study of consumer attitudes toward genetic testing and newborn screening for deafness
}

\author{
Sarah K. Burton, $M S^{1}$, Kara Withrow, MS $S^{2}$, Kathleen S. Arnos, $P h D^{1}$, Andrea L. Kalfoglou, PhD ${ }^{3}$, Arti Pandya, MD ${ }^{2}$
}

\begin{abstract}
Purpose: Progress in identifying genes for deafness together with implementation of universal audiologic screening of newborns has provided the opportunity for more widespread use of molecular tests to detect genetic forms of hearing loss. Efforts to assess consumer attitudes toward these advances have lagged behind. Methods: Consumer focus groups were held to explore attitudes toward genetic advances and technologies for hearing loss, views about newborn hearing screening, and reactions to the idea of adding molecular screening for hearing loss at birth. Focus group discussions were recorded, transcribed and analyzed. Results: Five focus groups with 44 participants including hearing parents of deaf children, deaf parents and young deaf adults were held. Focus group participants supported the use of genetic tests to identify the etiology of hearing loss but were concerned that genetic information might influence reproductive decisions. Molecular newborn screening was advocated by some; however, others expressed concern about its effectiveness. Conclusion: Documenting the attitudes of parents and other consumers toward genetic technologies establishes the framework for discussions on the appropriateness of molecular newborn screening for hearing loss and informs specialists about potential areas of public education necessary prior to the implementation of such screening. Genet Med 2006:8(12):779-783.
\end{abstract}

Key Words: hearing loss, deafness, molecular testing, genetic testing, focus groups, consumer attitudes, newborn screening

Hearing loss affects approximately 3-4:1,000 newborns and by the end of the first decade of life, an additional 5-9 cases of permanent childhood hearing loss are identified for every 10 cases present at birth, making it one of the most common birth defects in the United States. ${ }^{1}$ Genetic factors account for an estimated $60 \%$ of profound hearing loss present at birth or in early childhood. ${ }^{2,3}$ To date, more than 100 genes involved in nonsyndromic and syndromic deafness have been mapped and over 40 genes have been cloned. ${ }^{4}$ More than half of nonsyndromic hearing loss in children can be attributed to mutations in a single gene, GJB2 (Gap Junction Beta 2), which codes for the connexin 26 protein. ${ }^{5}$

In 1999, U.S. federal legislation mandated the establishment of early hearing detection and intervention (EHDI) programs in every state. The goals of the state-based EHDI programs are to screen all newborns for hearing before one month of age using audiologic techniques, diagnose the hearing loss no later than three months of age and coordinate appropriate interven-

\footnotetext{
From the ${ }^{I}$ Genetics Program, Department of Biology, Gallaudet University, Washington, DC, ${ }^{2}$ Department of Human Genetics, Virginia Commonwealth University, Richmond, Virginia; ${ }^{3}$ Social and Behavioral Research Branch, National Human Genome Research Institute, $\mathrm{Na}$ tional Institutes of Health, Bethesda, Maryland.

A. Pandya, Associate Professor, Department of Human Genetics and Pediatrics, Medical College of Virginia at Virginia Commonwealth University, PO Box 980033, Richmond, VA 23298.
}

Submitted for publication July 20, 2006.

Accepted for publication September 22, 2006.

DOI: 10.1097/01.gim.0000250501.59830.ff tion services no later than six months of age.6,7 Discussions about how to best incorporate genetic services into the current EHDI program framework have been initiated. ${ }^{8-11}$ While auditory hearing screening is an effective and relatively inexpensive way to detect hearing loss in the newborn period, a major limitation is that all forms of prelingual hearing loss are not expressed at birth and could be missed by EHDI programs based solely on audiologic testing. ${ }^{1}$ A parallel molecular screening strategy to help detect common forms of late onset prelingual genetic hearing loss could provide a useful complement to audiologic screening. It also has the advantage of prompt establishment of the etiology for some of the more common causes of profound deafness, such as GJB2 mutations.

Previous studies have documented the tendency of the deaf community, a small group of deaf individuals who view deafness from a cultural or sociological perspective as opposed to a medical condition, ${ }^{12}$ to view genetic testing for deafness as something that will have a negative impact on their community. ${ }^{13,14}$ However, more recent studies indicate that members of both the hearing and deaf communities may be amenable to genetic testing to identify deafness in newborns. ${ }^{15,16}$ Parents of deaf or hard-of-hearing children have been shown to have a positive attitude toward genetic testing for deafness, including prenatal testing, ${ }^{17,18}$ but most would not use this information to terminate an affected pregnancy. ${ }^{17} \mathrm{~A}$ recent study which used in-depth interviews to examine the attitudes of a small sample of deaf individuals toward genetic testing and informed choice found that support for genetic testing for deafness was clear in the presence of full informa- 


\section{Burton et al.}

tion about all relevant aspects of deafness. ${ }^{19}$ In this study, participants emphasized informed choice and maintaining optional services (such as those providing prenatal diagnosis of deafness) for those who may wish to use them, but did not express much support for prenatal diagnosis or termination of pregnancy for deafness. Studies of hearing young adults and expectant mothers who had no prior exposure to deaf individuals found that the majority reported positive attitudes toward genetic testing for deafness and a general interest in newborn and prenatal genetic testing. ${ }^{15,20}$

Given the impending increase in the utilization of molecular testing for hearing loss for preconception and prenatal counseling and as an adjunct to newborn audiologic hearing screening, we sought to understand the opinions of parents of deaf children and deaf individuals have about these issues. Specifically, we explored focus groups participants' perceptions of three general topics: 1) genetic testing for hearing loss; 2) audiologic newborn screening and early identification and intervention; and 3) the potential to add molecular testing to newborn audiologic screening protocols.

\section{MATERIALS AND METHODS}

\section{Recruitment}

Participants were recruited through the Laurent Clerc National Deaf Education Center and the undergraduate program at Gallaudet University, and the genetics clinics at both Gallaudet University and Virginia Commonwealth University. The study coordinators used flyers, letters, email advertisements, and phone calls to recruit participants. Hearing parents were eligible if they had at least one deaf or hard of hearing child who was in elementary school. The deaf adults were eligible if they were either a parent of a child who was in elementary school or if they were a student at Gallaudet University who was unmarried, without children and between 18 and 30 years of age. A systematic effort was made to recruit participants of both genders, of varying race/ethnicity, and educational levels. Participants were compensated $\$ 30$.

\section{Procedures}

Two experienced focus group moderators were contracted and matched to each group based on hearing/communication status and cultural affiliation. An experienced, culturally deaf moderator led the groups of deaf individuals, which were held in American Sign Language. Certified sign language interpreters provided simultaneous sign-to-voice interpretation for the three focus groups with deaf participants. Sessions lasted two hours or longer in those sessions with more participants, to provide enough time to ensure that the opinions of all participants were documented. All sessions were audio taped and depending on group size, one or two investigators were present to take notes and capture nonverbal cues. Investigators present during deaf sessions were fluent in ASL. Moderators followed detailed focus group discussion guides developed by the investigators along with follow-up probes to explore each issue in depth. Approval for the study was obtained from the Institu- tional Review Boards of Research Triangle Institute, Gallaudet University and Virginia Commonwealth University.

The moderators began each focus group by prompting a discussion of the participants' general understanding of genetic evaluation and testing. No background information on these topics was provided. Participants were asked to talk about their thoughts on genetic technology with respect to evaluation for hearing loss and deafness including diagnostic testing strategies based on their previous experience and current knowledge. Participants were queried about their knowledge and experience with EHDI. Each group was asked to consider the benefits and limitations of these programs and whether adding universal molecular screening for deafness genes would be an asset to existing newborn screening programs.

Some of the limitations of our study include a relatively small sample size, which could introduce a self-selection bias, since participants were informed of the topic of the focus group at the time of their recruitment. In the parent and student groups, a number of participants knew each other, which may have influenced their responses to the moderator's questions.

\section{Data analysis}

The focus groups were audio taped and transcribed. Standard techniques were used to improve the accuracy and reliability of the transcripts. ${ }^{19}$ Two members of the research team reviewed the transcripts to correct transcription errors and clarify inaudible speech and misattributed statements. Four members of the research team independently reviewed the data to identify themes and develop a codebook. ${ }^{21}$ Codes, subcodes, and definitions, including inclusion and exclusion criteria, were reviewed and revised by the research team to identify overlapping or missing codes. Quotations that illustrated the main themes were identified during the coding process. The process was subjected to an external audit by a consultant who independently coded the transcripts and examined them for accuracy and reliability. The transcripts were then electronically coded using NVivo (version 2.0) software (QSR International, Doncaster, Victoria, Australia), and themes, trends, and patterns were identified.

\section{RESULTS}

\section{Participants}

We conducted five focus groups with ethnically diverse participants ranging in size from 5 to 16 individuals (Table 1). Two of the focus groups consisted of hearing parents of young deaf children, one consisted of deaf parents of hearing and deaf children, and two groups were deaf unmarried adults who were students from Gallaudet University. Among parents, 11/20 participants reported receiving a genetic evaluation for their child's hearing loss. Of the deaf adults, 2/24 participants reported receiving a genetic evaluation or had genetic testing for hearing loss. Deaf adults were students at Gallaudet University and did not have children, which may have influenced their attitudes and perceptions. 
Table 1

Focus group demographics

\begin{tabular}{|c|c|c|c|c|c|}
\hline Location & Recruitment source & No. of participants & $\begin{array}{c}\text { Sex ratio } \\
(\text { male/female })\end{array}$ & Age range & Ethnicity \\
\hline Richmond, VA & VCU Genetics Clinic & $\begin{array}{l}5 \text { hearing parents of child with } \\
\text { hearing loss }\end{array}$ & $4 \mathrm{~F} / 1 \mathrm{M}$ & $30-45$ & 5 Caucasian \\
\hline Washington, DC & $\begin{array}{l}\text { Gallaudet Genetics Clinic and Laurent } \\
\text { Clerc National Deaf Education } \\
\text { Center }\end{array}$ & $\begin{array}{l}9 \text { hearing parents of child with } \\
\text { hearing loss }\end{array}$ & $8 \mathrm{~F} / 1 \mathrm{M}$ & $30-45$ & $\begin{array}{l}5 \text { African-American, } 1 \text { Hispanic, } \\
3 \text { Caucasian }\end{array}$ \\
\hline Washington, DC & $\begin{array}{l}\text { Gallaudet University Clinics and } \\
\text { University Faculty/Staff }\end{array}$ & $\begin{array}{l}6 \text { deaf parents of deaf or } \\
\text { hearing children }\end{array}$ & $6 \mathrm{~F}$ & $25-45$ & $\begin{array}{l}1 \text { African-American, } 1 \text { Pacific } \\
\text { Islander, } 4 \text { Caucasian }\end{array}$ \\
\hline Washington, DC & Gallaudet University Student Body & $\begin{array}{l}16 \text { deaf adults, unmarried } \\
\text { without children }\end{array}$ & $7 \mathrm{~F} / 9 \mathrm{M}$ & $18-30$ & $\begin{array}{l}4 \text { African-American, } 2 \text { Hispanic, } \\
3 \text { Asian, } 7 \text { Caucasian }\end{array}$ \\
\hline Washington, DC & Gallaudet University Student Body & $\begin{array}{l}8 \text { deaf adults, unmarried } \\
\text { without children }\end{array}$ & $4 \mathrm{~F} / 4 \mathrm{M}$ & $18-30$ & $\begin{array}{l}1 \text { African, } 1 \text { African-American, } 1 \\
\text { Hispanic, } 5 \text { Caucasian }\end{array}$ \\
\hline
\end{tabular}

\section{Perceptions about genetic testing for deafness}

Regardless of the hearing status of participants, responses to open-ended questions about their general understanding and how they felt about genetic testing for hearing loss were equally divided between positive, negative and indifferent. Most agreed that advances in genetic technology, and improved understanding of deafness genes represents positive progress. Many parents used words such as "great," "it's a very good thing," and "an option that is good for parents" to describe their feelings about genetic testing. On the whole, all groups regarded the use of genetic testing to assist in diagnosing the hearing loss and/or confirming the etiology as a benefit for parents of deaf children. Additionally, several hearing parents felt that learning the etiology of the hearing loss helps parents deal with the grief, guilt, and anxiety resulting from the diagnosis of hearing loss. Deaf adults expressed positive motivations for seeking genetic testing, including to clarify their own self-identity and to prepare for future children.

"I think it's very important for us to know who we are, and how we became deaf. If we didn't have that opportunity, it would be like part of us is missing. Also, it's nice to know if my kids are going to be deaf or not. If we know what to expect, then we are ready to make the right decisions when it comes to schooling or job choices." (Deaf unmarried woman)

A number of deaf parents believed that the availability of genetic testing for their children was valuable, and they stressed the importance of educating other parents about the value of genetic testing. Some parents expressed concern about learning information through genetic testing that they might not wish to know. Genetic knowledge was described as a 'Pandora's box' that could be opened through the exploration of genes.

Both deaf and hearing parents and deaf unmarried adults expressed other concerns about the reliability of test results and the common misconception that genetic testing always provides clear answers about the cause of the hearing loss.

"There should be some sort of caveat saying there is no guarantee that the genetic testing will give you answers.
That is what happened with my kids. We still don't know [the exact cause of their deafness] after all the testing .... There are still hundreds of other genes that haven't been discovered. It would [have helped] manage our expectations." (Hearing mother of two deaf children)

Attitudes toward carrier testing were evenly split between positive and negative, whereas attitudes toward prenatal diagnosis tended to be more negative. Many participants expressed concern about the potential for negative influence on reproductive decision-making and feared couples may decide not to have children or to terminate a pregnancy because of the increased possibility that a child may be deaf or hard of hearing.

"One of the real issues with genetic testing that bothers me is that ... had I known before [my child was born], I may have made decisions that I may have regretted for the rest of my life." (Hearing father of a deaf child)

Despite these concerns, participants in all groups were interested in understanding the chances that their future children, their grandchildren, and the children of the extended family members might be deaf or hard of hearing. While they worried this information would cause some individuals to make "bad decisions," they expressed a great deal of interest in learning about the potential birth of a deaf child as early as possible so they may begin to prepare for that child's language and education.

While most participants readily point out the benefits of genetic testing, they often directed the discussion to issues they consider to be of higher priority. This served as a key point of divergence between the deaf and hearing groups. For hearing parents, technologies which provide more information about the hearing loss were viewed as less helpful than those which focus on finding a solution for the hearing loss (i.e., having a means to pay for a hearing aid is more important than having a technology which helps with understanding etiology). Hearing parents repeatedly stated that finding solutions is the 'ultimate goal' of genetic research. They understood that this technology would likely not provide treatment modalities for their own children, but were interested in assisting in research that would provide better care and treatment for children in the future. 
"Answers are good, but solutions are more important. What does testing for testing sake and knowing [mean] unless it leads to something? To me, it is useless. I am looking for solutions at this point." (Hearing father of a deaf child)

This is in stark contrast to the opinions of deaf parents and the deaf unmarried adults, who repeatedly stated that they were opposed to using genetic technology to find a cure for deafness or to eliminate the "deaf gene." Deaf individuals were much more interested in using genetic testing to help them understand the cause of hearing loss in themselves and their children.

"To use [genetic testing] for the purpose of eliminating the deaf gene or preventing the growth of the deaf population .... I think that is very negative. It is negative if you abort or terminate the pregnancy to stop the genetic trait of deafness from being passed on. If I, as a deaf person, had a deaf child, I would be proud to pass on my traditions."

(Deaf unmarried man)

\section{Perceptions of newborn hearing screening}

Most participants, both deaf and hearing had a basic understanding of the goals and methods used for audiologic newborn hearing screening in their state. Newborn screening and early intervention were clearly recognized as a benefit by all participants in all focus groups.

"If parents don't find out until later that their child is deaf, the child does not have any access to language. I think that is why deaf children's English is so poor, because they really aren't given the foundations of the language early in life. Hearing screening is good because parents can be prepared and start as early as possible - the earlier, the better."

(Deaf unmarried woman)

Even those parents whose children were born before newborn hearing screening programs had been instituted in their states were acutely aware of the benefits of early identification of hearing loss.

\section{Perceptions of molecular newborn screening}

When queried about the possibility of including genetic tests for common forms of hearing loss as part of molecular newborn screening, comments lacking enthusiasm outweighed positive comments. Participants liked the idea of including genetic testing because it had the potential to identify at risk children missed by audiologic screening, but they were not sure testing all children was worth the expense they perceived to be associated with such testing. This sentiment was countered by other parents who were often very passionate in their beliefs that early identification and intervention should outweigh concerns about expense.

"How much more money you have to put into children [identified later] versus if you start early. The cost in the long run is way more in terms of. education and functionality of that child." (Hearing mother of a deaf child)
"A lot of kids aren't diagnosed until they are two because ... they [were missed by] early hearing screening. Why not alert the parents so that they can be better prepared?" (Hearing mother of deaf child)

Many of the positive comments about molecular newborn screening for deafness came from the deaf parents.

"There is hearing screening tests for all babies, hearing or deaf. So it should be the same for genetic testing. Everybody, all babies, should have genetic testing." (Deaf mother of a deaf child)

All groups discussed whether explicit consent for newborn molecular screening for genes for deafness is necessary. Slightly more than half of the parents indicated that explicit consent should be obtained before such testing is done; however many felt that this consent could be included in the general hospital consent used for other, current newborn screening tests.

\section{DISCUSSION}

Qualitative research methodologies are increasingly used as a powerful tool to explore and understand ethical and social issues, ${ }^{22}$ such as genetic discrimination and attitudes toward newborn screening for genetic conditions. ${ }^{23-25}$ Assessing attitudes of the consumer about potential applications of genetic testing is a valuable form of "community consultation" from the population which is most likely to be impacted by the implementation of such testing. With respect to testing deafness genes, elucidating the attitudes of the parents of children with hearing loss and deaf adults with and without children not only provides us with an opportunity to understand issues that are important to them, but also serves as a starting point for the process of public education where community concerns can be addressed.

Through focus group discussions we sought to collect qualitative data on how parents of deaf children and deaf adults feel about genetic testing, audiologic newborn hearing screening, and the potential to offer molecular newborn testing for deafness genes in conjunction with audiologic screening programs. While these specific topics were identified by the investigators as being important, the results of our discussion with the focus group participants validated the significance of these topics to consumers. In addition, the use of open-ended questions in these focus groups permitted participants to guide the discussion toward topics of greatest interest to them.

Our results not only support data from previous studies using quantitative and qualitative methodologies, including those which document the trends toward acceptance of genetic testing by the hearing and deaf communities and parents of deaf children, ${ }^{14-20}$ but to further serve in documenting attitudes of these groups toward potential future applications of genetic technologies. The current study which focused on hearing parents of deaf children, deaf parents and single deaf adults found that these groups had an overall positive attitude toward genetic testing for deafness, further indicating the 
trend for increased interest and support for genetic testing from the deaf community. However, it is important to note that motivations for seeking genetic testing differed between deaf and hearing groups. Hearing parents felt that the test results helped them to accept the diagnosis of hearing loss in their children, while deaf adults sought genetic testing because of their curiosity to understand the cause of their hearing loss. Concerns centered on test reliability and a general sense of apprehension toward having too much information. Deaf parents and adults continued to express some fear that these advances may be used to eliminate or "cure" deafness while hearing parents expressed interest in more effective treatments and cited finding a "cure" as a key motivation for participating in genetic research. Although participants were concerned about potential negative applications of preconception and prenatal genetic diagnosis of deafness, they cited several positive applications, including the ability of parents to plan and prepare for the needs of a deaf child.

It is difficult to draw definite conclusions about the acceptance of adding universal molecular screening for hearing loss based on our data, although many participants did express interest due to the advantages of early confirmation of hearing loss and identification of an etiology. Nance et al. ${ }^{1,26}$ suggest that the addition of molecular newborn screening as a complement to audiologic newborn screening will help identify infants with late-onset prelingual hearing loss. Some parents were concerned about cost effectiveness due to their perception that hearing loss is rare. However, it is important to note that the incidence of congenital hearing loss is much higher in comparison to all the disorders currently screened for at birth. The ability to identify infants with late onset prelingual hearing loss that are likely to be missed by audiologic newborn screening and provide appropriate surveillance and intervention might outweigh the cost of screening all infants. However, we are presently not aware of such a program in North America making it difficult to specifically comment on the cost-benefit ratio. Surprisingly, many deaf parents were accepting of molecular screening for deafness genes provided that all babies were tested and the program was not designed to "cure" or eliminate deafness.

Our study provides several new insights into the views of hearing parents and deaf adults on key issues related to genetic testing for deafness and newborn hearing screening. The potential application of genetic testing for making reproductive decisions is a sensitive topic. Understanding the different motivations to seek genetic testing or reservations that hearing parents and deaf adults have offers the provider an opportunity to educate the client and present realistic expectations. Our findings demonstrate that the opinions held by hearing parents and deaf adults do not fall into a clear pattern of "good" and "bad" uses of genetic technology. The issues and concerns elicited by this study should be used to enhance the communication and information provided to our clients, so that they can make informed decisions about the use of new genetic technologies.

\section{ACKNOWLEDGEMENTS}

This study was supported by grant number 1 R01 DC005831 to AP from the National Institute on Deafness and Other Communication Disorders (NIDCD), National Institutes of Health (NIH). SKB, KSA and AP are also supported by NIDCD/NIH grants 1 R01 DC006707 to KSA. The authors wish to thank Mr. Alfred Sonnenstrahl for serving as a focus group moderator and all of the focus group participants for their assistance with this study.

\section{References}

1. Morton CC, Nance WE. Newborn hearing screening-a silent revolution. N Engl J Med 2006;354:2151-2164.

2. Toriello HV, Reardon W, Gorlin RF, editors. Hereditary Hearing Loss and Its Syndromes. 2nd ed. New York: Oxford University Press; 2004.

3. Petit C. Memorial lecture-hereditary sensory defects: from genes to pathogenesis. Am J Med Genet A 2004;130:3-7.

4. VanCamp G, Smith RJH. Hereditary Hearing Loss Homepage. Available at: http:// webhost.ua.ac.be/hhh/. AccessedJanuary 20, 2006.

5. Kenneson A, Van Naarden BK, Boyle C. GJB2 (connexin 26) variants and nonsyndromic sensorineural hearing loss: a HuGE review. Genet Med 2002;4:258-274.

6. White KR. The current status of EHDI programs in the United States. Ment Retard Dev Disabil Res Rev 2003;9:79-88.

7. Joint Committee on Infant Hearing, American Academy of Audiology, American Academy of Pediatrics, American Speech-Language-Hearing Association, and Directors of Speech and Hearing Programs in State Health and Welfare Agencies. Year 2000 position statement: principles and guidelines for early hearing detection and intervention programs. Pediatrics. 2000;106:798-817.

8. Genetic Evaluation of Congenital Hearing Loss Expert Panel. Genetics Evaluation Guidelines for the Etiologic Diagnosis of Congenital Hearing Loss. ACMG statement. Genet Med 2002;4:162-171.

9. White KR. Early hearing detection and intervention programs: opportunities for genetic services. Am J Med Genet A 2004;130:29-36.

10. Schimmenti LA, Martinez A, Fox M, et al. Genetic testing as part of the early hearing detection and intervention (EHDI) process. Genet Med 2004;6:521-525.

11. Robin NH. Genetic testing for deafness is here, but how do we do it? Genet Med 2004;6:463-464.

12. Padden C. Deaf in America, Voices from a culture. Cambridge (MA): Harvard University Press; 1998.

13. Middleton A, Hewison J, Mueller RF. Attitudes of deaf adults toward genetic testing for hereditary deafness. Am J Hum Genet 1998;63:1175-1180.

14. Stern SJ, Arnos KS, Murrelle L, Welch KO, et al. Attitudes of deaf and hard of hearing subjects toward genetic testing and prenatal diagnosis of hearing loss. J Med Genet 2002;39:449-453

15. Martinez A, Linden J, Schimmenti LA, Palmer CG. Attitudes of the broader hearing, deaf, and hard-of-hearing community toward genetic testing for deafness. Genet Med 2003;5:106-112.

16. Taneja PR, Pandya A, Foley DL, Nicely LV, et al. Attitudes of deaf individuals toward genetic testing. Am J Med Genet A 2004;130:17-21.

17. Brunger JW, Murray GS, O’Riordan M, Matthews AL, et al. Parental attitudes toward genetic testing for pediatric deafness. Am J Hum Genet 2000;67:1621-1625.

18. Parker MJ, Fortnum HM, Young ID, Davis AC. Genetics and deafness: what do families want? J Med Genet 2000;37:E26.-

19. Guillemin M, Gillam L. Attitudes to genetic testing for deafness: the importance of informed choice. J Genet Couns 2006;15:51-59.

20. Ryan M, Miedzybrodzka Z, Fraser L, Hall M. Genetic information but not termination: pregnant women's attitudes and willingness to pay for carrier screening for deafness genes. J Med Genet 2003;40:E80.

21. MacQueen KM, McLellan E, Milslen B. Codebook development for team-based qualitative analysis. Cult Anthro Methods 1998;31-36.

22. Barbour RS. The newfound credibility of qualitative research? Tales of technical essentialism and co-option. Qual Health Res 2003;13:1019-1027.

23. Lehmann LS, Weeks JC, Klar N, Garber JE. A population-based study of Ashkenazi Jewish women's attitudes toward genetic discrimination and BRCA1/2 testing. Genet Med 2002;4:346-352.

24. Campbell E, Ross LF. Parental attitudes regarding newborn screening of PKU and DMD. Am J Med Genet A 2003;120:209-214.

25. Campbell E, Ross LF. Professional and personal attitudes about access and confidentiality in the genetic testing of children: a pilot study. Genet Test 2003;7:123-130.

26. Nance WE, Lim BG, Dodson KM. Importance of congenital cytomegalovirus infections as a cause for pre-lingual hearing loss. J Clin Virol 2006;35:221-225. 